\title{
Influence of nanoparticles on the morphology, thermal stability and air permeability of electrospun polylactic-acid fibres
}

\author{
Jenny Alongi, ${ }^{*}$ Merima Pošković
}

*Department of Materials Science and Chemical Engineering, Polytechnic of Turin, Alessandria branch, Viale Teresa Michel 5, 15121, Alessandria, Italy; tel/fax: +39 $0131 \quad 229337 /+39 \quad 0131 \quad 229399 ; \quad$ e-mail: jenny.alongi@polito.it; merima.poskovic@polito.it

(Received: 07 November, 2010; published: 30 July, 2011)

\begin{abstract}
Polylactic-acid (PLA) and PLA-clay fibres have been produced from solution of 1,1,1,3,3,3-hexafluoro-2-propanol by electrospinning. Nanoclays having different aspect ratio, namely a montmorillonite and a sepiolite, have been added and dispersed within the polymer matrix in order to enhance the thermal stability and air permeability of PLA. The influence of the polymer molecular weight, the solution viscosity and conductivity on the morphology of the fibres has been investigated. Electron microscopy has shown that fibre diameter and the presence of beads defects in the fibres depend on the type of clay added to the polymer matrix. The thermal stability in nitrogen and in air has been drastically enhanced for the presence of the clays as compared with neat polymer. Finally, permeability tests performed on the electrospun condensed fibres pointed out that PLA-clay fibres exhibit a lower permeability to air (up to 90\%) with respect to neat PLA fibres.

Keywords: PLA; nanoclays; electrospinning; fibres.
\end{abstract}

\section{Introduction}

In recent years, both the academic and industrial research activity in the textile field has been focused on the electrospinning technique which is a versatile and unique process capable of producing continuous artificial filaments in order to make micro and nanofibres $(50-700 \mathrm{~nm})$ of polymers, using an electric field. This electrostatic process uses a high voltage electric field to form solid fibres from a polymer fluid jet (solution or melt) delivered by a millimeter-scale nozzle [1-3]. Generally, electrospun nanofibres are collected in non-woven structures (mats) characterized by a large surface area per unit mass and small pore size. Numerous polymers have been successfully electrospun into ultrafine fibres mainly working in solution, including polyamides [4,5], polyesters [6-8], polylactides [9-12], cellulosic derivatives [13-16], water soluble polymers such as polyethyleneoxide (PEO) [17-20], polymer blends or polymers containing solid nanoparticles or functional small molecules. Although electrospun nanofibres loaded by nanofillers have been developed for biological applications [11, 13], to the best of our knowledge, only few studies about the morphology and the thermal stability have been reported in the literature [20].

Currently, the possibility of introducing nanoparticles within nanofibres plays a fundamental role in order to improve their chemical and physical properties; electrospinning has gained an increasing interest in recent years. When a nanoparticle is homogeneously dispersed within a polymer, the resulting 
nanocomposite often exhibits remarkable improvements of mechanical, thermal, optical and physicochemical properties as compared to either the neat polymer or conventional composites (micro- and macrocomposites) [21-23]. Such improvements include increased mechanical strength and heat resistance, decreased gas permeability and flammability.

Although the most important results in the field of nanocomposites concern plastic materials, recently the interest for the preparation of nanocomposite fibres has reached also the textile field: by electrospinning process, for example, polymers loaded by carbon nanotubes [17, 24, 25] and montmorillonites [26-28] have been produced. Polylactic acid (PLA) is a thermoplastic polymer, which exhibit good mechanical properties and biodegradability features [29, 30]. Only few papers describe the use of electrospinning process to prepare PLA fibres characterized by a high thermal stability and low permeability [30-31].

In the present work, PLA and PLA-clay fibres have been produced by electrospinning in solution and their morphology, thermal stability and air permeability have been thoroughly investigated. For this purpose, two nanoclays, characterized by a different aspect ratio (namely, a montmorillonite and a sepiolite) have been dispersed within the PLA matrix. The influence of the polymer molecular weight, the solution viscosity and the conductivity on the morphology of the fibres has been studied.

\section{Results and discussion}

\section{Morphology}

In order to verify the effect of the flow rate on the morphology of the neat and loaded fibres produced by electrospinning in solution, Scanning Electron Microscopy (SEM) was employed.

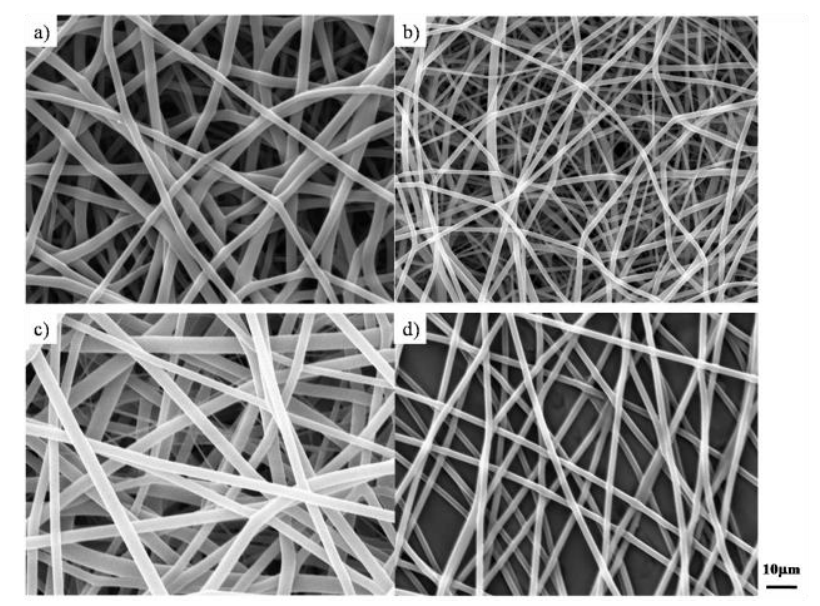

Fig. 1. SEM micrographs of PLA1 and PLA2 spun at $0.005 \mathrm{ml} / \mathrm{min}(\mathrm{a}, \mathrm{c})$ and $0.010 \mathrm{ml} / \mathrm{min}(\mathrm{b}, \mathrm{d})$.

SEM magnifications of electrospun PLA1 and PLA2 nanofibres (at 3000X) at different flow rates $(0.005$ and $0.010 \mathrm{ml} / \mathrm{min}$, respectively) have been reported in Figure 1: in both process conditions, the fibres exhibit a smooth and regular surface. By increasing the flow rate, the diameter of fibres increases, as reported in Table 2 and according to the literature [36]. Comparing PLA1 and PLA2, it is possible to observe that the molecular weight affects the process: indeed, a PLA characterized by a lower 
molecular weight produces fibres characterized by a smaller diameter, namely, PLA2. Table 3 shows that PLA2, having a lower molecular weight than PLA1, give a solution with a lower viscosity and conductivity. These two parameters of the solution influence remarkably the electrospinning process of PLA. Furthermore, as observable in Figures 1c and d, the low molecular weight and thus the corresponding viscosity of PLA2 can contribute to form two groups of fibers characterized by a different diameter.

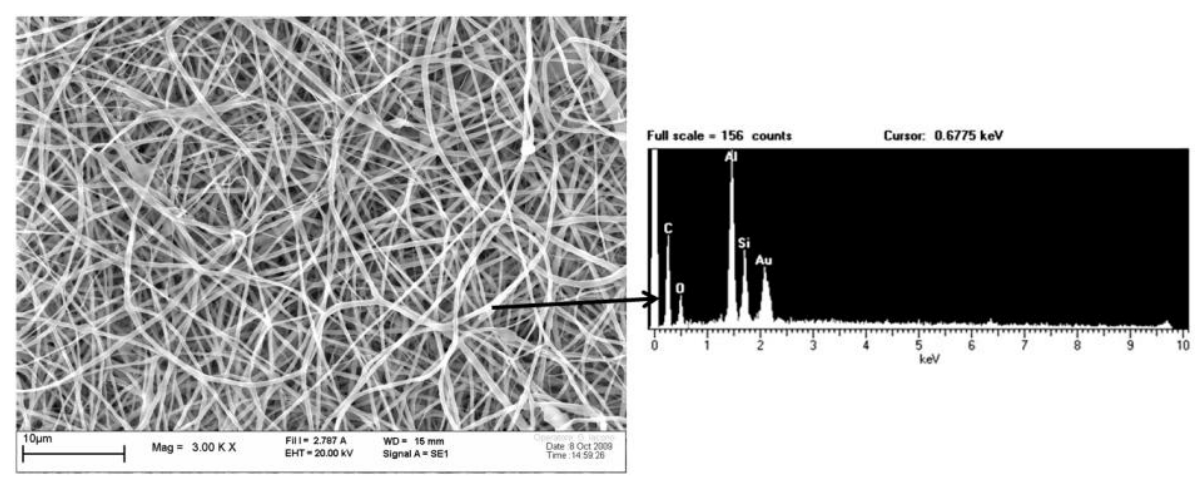

(a)

(b)

Fig. 2. SEM micrographs of electrospun PLA1-10C30B at $0.005 \mathrm{ml} / \mathrm{min}$ (a) and corresponding EDS analysis (b).

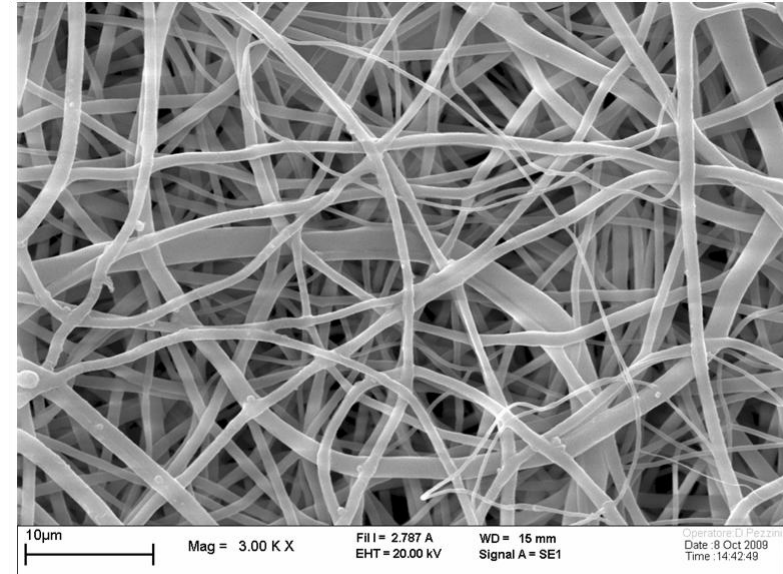

(a)

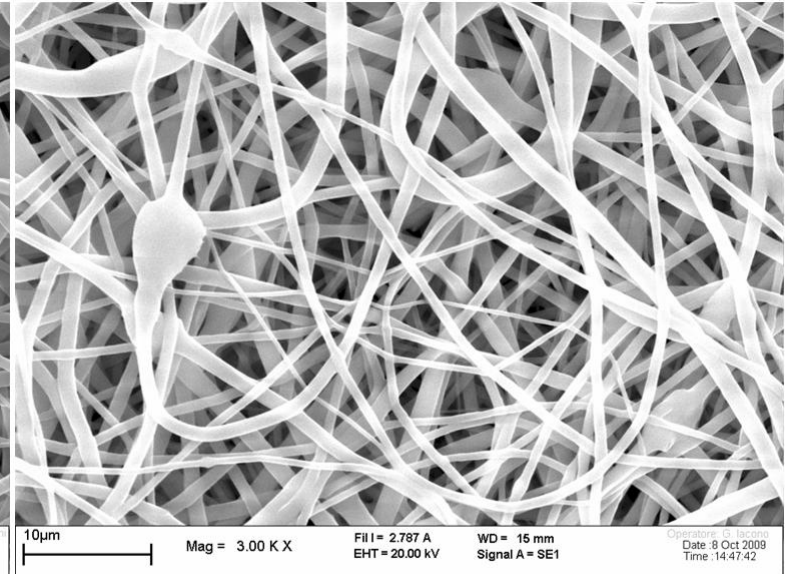

(b)

Fig. 3. SEM micrographs of PLA2-5CD1 (a) and PLA2-10CD1 (b).

SEM images of PLA1-10C30B (Figures 2a and 2b), PLA2-5CD1 and PLA2-10CD1 (Figures $3 a$ and $3 b$, respectively) spun at $0.005 \mathrm{ml} / \mathrm{min}$ show a large number of beads defects due to the presence of the filler as confirmed by EDS analysis (Figure $2 b$ ) where beads defects rich in $\mathrm{Si}$ and $\mathrm{Al}$ elements are well distinguishable. As for neat PLA1 and PLA2, the fibre diameter of also PLA1-C30B and PLA2-C30B depends on the molecular weight of the polymer as well as the viscosity (Tables 1 and 2). In addition, also for PLA1-C30B and PLA2-C30B fibres, the flow rate affects the fibre diameter: by increasing the flow rate, fibre diameter increases. In PLA2-5CD1 and PLA2-10CD1 fibres, the bead defects are more evident and bigger as compared with PLA-C30B fibres (both PLA1 and PLA2). Furthermore, regarding the effect of clay amount, sepiolite based-fibres showed that increasing clay concentration, the 
diameter of the fibres decreases $(0.92$ vs. $1.12 \mu \mathrm{m}$ and 1.45 vs. $2.15 \mu \mathrm{m}$ for PLA25CD1 and PLA2-10CD1, respectively, at flow rate of 0.005 and $0.010 \mathrm{ml} / \mathrm{min})$. In conclusion, being equal the amount of nanoclay (10wt.-\%), the aspect ratio of nanoclay (and, consequently, the dispersion of the clay within PLA) seems to influence the formation of beads defects.

Tab. 1. Electrospinning parameters modified during the process.

\begin{tabular}{cccc}
\hline Formulation & \multicolumn{2}{c}{ Diameter $^{*}[\mu \mathrm{m}]$} \\
\hline & $\begin{array}{c}\text { Flow rate } \\
{[\mathrm{ml} / \mathrm{min}]}\end{array}$ & 0.005 & 0.010 \\
\hline PLA1 & & 0.84 & 1.21 \\
PLA2 & 0.62 & 0.80 \\
PLA1-10C30B & 0.51 & 0.60 \\
PLA2-10C30B & 0.40 & 0.47 \\
PLA2-5CD1 & 0.92 & 1.45 \\
PLA2-10CD1 & 1.12 & 2.15 \\
\hline
\end{tabular}

* Diameter was evaluated as average value on the basis of the statistical investigation on 100 fibres using IMAGE J software from SEM images (see Experimental part).

Tab. 2. Viscosity and conductivity values of PLA fibres electrospun at $0.005 \mathrm{ml} / \mathrm{min}$.

\begin{tabular}{ccc}
\hline Formulation & $\begin{array}{c}\text { Viscosity } \\
{[\mathrm{Pa} \mathrm{s}]}\end{array}$ & $\begin{array}{c}\text { Conductivity } \\
{[\mu \mathrm{s} / \mathrm{cm}]}\end{array}$ \\
\hline PLA1 & 0.80 & 0.91 \\
PLA2 & 0.65 & 0.44 \\
PLA1-10C30B & 1.64 & 11.13 \\
PLA2-10C30B & 1.21 & 9.97 \\
PLA2-5CD1 & 0.42 & 0.65 \\
PLA2-10CD1 & 0.90 & 0.78 \\
\hline
\end{tabular}

\section{Thermal stability}

In order to investigate the effect of the clay on the thermal stability of PLA, TGA measurements have been carried out on the electrospun fibres of both neat PLA and clay composites in inert and oxidant atmospheres. TG and dTG curves in nitrogen and in air are plotted in Figure 4 ( $4 a$ and $4 b$, respectively) whereas the obtained data are collected in Table 3. In both the atmospheres, PLA decomposes through a single degradation step with a maximum of weight loss at ca. $355^{\circ} \mathrm{C}$ and a final residue at $800{ }^{\circ} \mathrm{C}$ in between $1-2 \mathrm{wt} .-\%$ regardless of the $\mathrm{D} / \mathrm{L}$ isomer content. As for PLA-clay fibres, it is possible to observe that both the clays play a protective role on the thermal degradation in nitrogen and thermo-oxidation in air of both PLA, in particular, a strong increase of Tonset5\% and Tmax together with a remarkable shifting of the decomposition at higher temperatures has been observed. Furthermore, the final residue at 400 and $800^{\circ} \mathrm{C}$ increases due to the presence of the clays.

\section{Air permeability}

Nanocomposites are well-known to decrease the permeability to gases due to the presence of the nanoparticles finely dispersed within the polymer matrix [22]. For this 
reason, the air permeability of the film prepared by electrospinning has been evaluated.

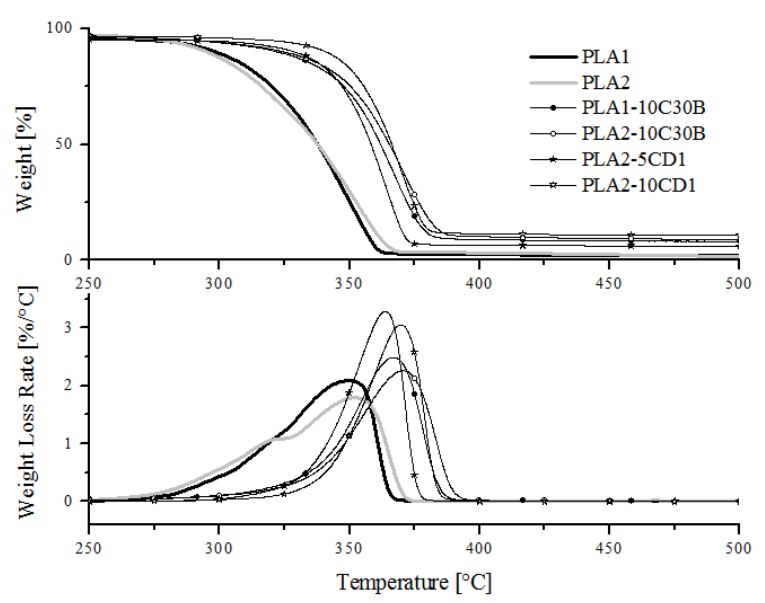

(a)

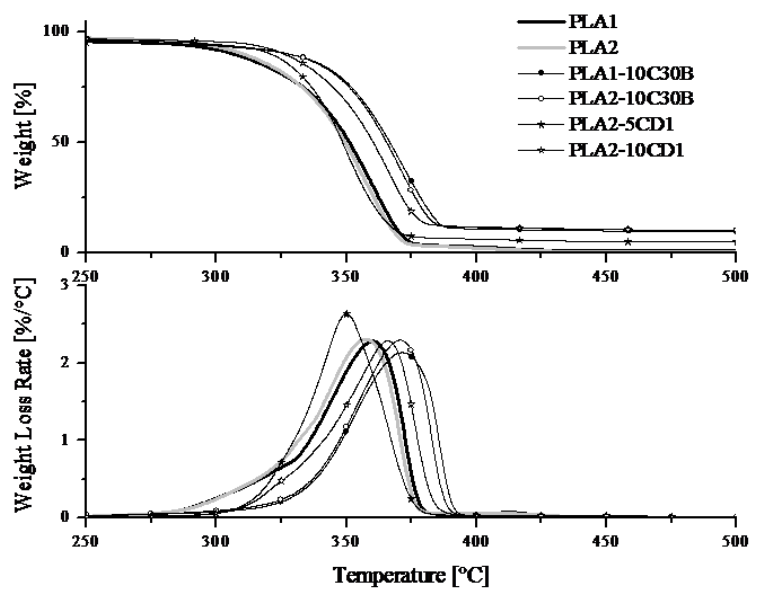

(b)

Fig. 4. TG and dTG curves of PLA and PLA-clay fibres in nitrogen (a) and in air (b).

Tab. 3. TGA data of PLA and PLA-clay fibres.

\begin{tabular}{lllll}
\hline Formulation & $\begin{array}{l}\mathrm{T}_{\text {onset5\% }} \\
{\left[{ }^{\circ} \mathrm{C}\right]}\end{array}$ & $\begin{array}{l}\mathrm{T}_{\max } \\
{\left[{ }^{\circ} \mathrm{C}\right]}\end{array}$ & $\begin{array}{l}\text { Residue } \\
\text { at } 400^{\circ} \mathrm{C}[\%]\end{array}$ & $\begin{array}{l}\text { Residue } \\
\text { at } 800^{\circ} \mathrm{C}[\%]\end{array}$ \\
\hline Nitrogen & & & & \\
\hline PLA1 & 269 & 350 & 2.5 & 2.0 \\
PLA2 & 277 & 352 & 3.2 & 2.0 \\
PLA1-10C30B & 286 & 367 & 9.0 & 8.4 \\
PLA2-10C30B & 288 & 371 & 10.1 & 8.6 \\
PLA2-5CD1 & 276 & 364 & 6.4 & 6.3 \\
PLA2-10CD1 & 315 & 370 & 11.4 & 10.3 \\
\hline Air & & & & \\
\hline PLA1 & 268 & 360 & 2.6 & 1.2 \\
PLA2 & 288 & 358 & 2.0 & 0.6 \\
PLA1-10C30B & 272 & 371 & 11.0 & 7.8 \\
PLA2-10C30B & 288 & 371 & 11.3 & 8.5 \\
PLA2-5CD1 & 271 & 350 & 6.0 & 5.0 \\
PLA2-10CD1 & 304 & 366 & 11.5 & 9.2 \\
\hline
\end{tabular}


Figure 5 reports GTR as function of the pressure and Table 4 lists the values of the permeability for neat PLA and PLA-clay fibres calculated using equation (1).

As expected, increasing the electrospinning time from 30 to $60 \mathrm{~min}$, the permeability of PLA films decreases significantly from 7.699 to $1.030 \mathrm{~m}^{3} \mathrm{~s} / \mathrm{m}^{2} \mathrm{~Pa}$. By adding C30B and maintaining the electrospinning time for $30 \mathrm{~min}$, GTR and consequently the permeability decrease in dramatic way up to $90 \%$ (Table 5). Comparing the films containing clay electrospun fibres at different times (namely, 30 and 60min), the permeability lowers although such decrease is probably due to the highest number of beads defects. Probably, the presence of the nanoclay affects the porosity of the electrospun membranes; indeed, as explained above, the fiber diameter decreases in the presence of clays and thus this could provoke a major overlapping of the same fibers with a consequent porosity reduction.

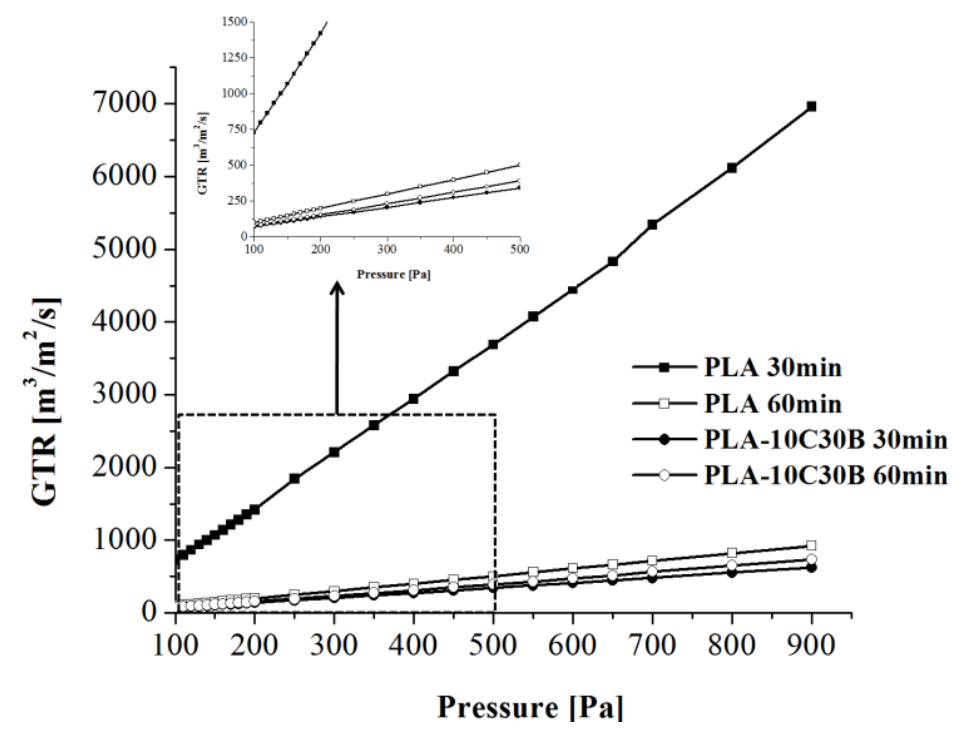

Fig. 5. Comparison of GTR between PLA and PLA-Cloisite30B electrospun films of 30 and 60 min (a) and zoom at low GTR (b).

Tab. 4. Permeability data of PLA and PLA-clay fibres.

\begin{tabular}{ll}
\hline Formulation & $\begin{array}{l}\text { Permeability } \\
{\left[\mathrm{m}^{3} \mathrm{~s} / \mathrm{m}^{2} \mathrm{~Pa}\right]}\end{array}$ \\
\hline PLA 30min & 7.699 \\
PLA 60min & 1.030 \\
PLA-10C30B 30min & 0.686 \\
PLA-10C30B 60min & 0.814 \\
\hline
\end{tabular}

* Permeability was calculated following the equation (1) (see Experimental part).

\section{Conclusions}

PLA and PLA-clay fibres have been produced by electrospinning in solution. Their morphology, the thermal stability and air permeability have been investigated. Morphological characterization showed that $\mathrm{C} 30 \mathrm{~B}$ allows to electrospin (at fixed flow rate) fibres characterized by a smaller diameter than CD1 for which a great amount of beads defects are distinguishable.

The thermal stability of these PLA-clay fibres in nitrogen and in air turned out highly enhanced for the presence of the clays as compared with neat polymer matrix; 
indeed, both the clays used (namely, a montmorillonite and a sepiolite) play a protective role on PLA increasing $\mathrm{T}_{\text {onset5\%, }} \mathrm{T}_{\max }$ and the residue at $800^{\circ} \mathrm{C}$. Furthermore, the air permeability has been dramatically decreased for the presence of the clays, up to $90 \%$.

\section{Experimental part}

\section{Materials}

Two poly(D, L-lactic acid) (PLA4042D ${ }^{\circledR}$ and PLA3000D ${ }^{\circledR}$ ) were supplied by NatureWorks ${ }^{\circledR}$ Inc. They differ for weight percentage of D-lactoyl unity and molecular weight as reported in Table 5. Such matrices were added of two different clays, namely Cloisite ${ }^{\circledR} 30 \mathrm{~B}$ (coded as $\mathrm{C} 30 \mathrm{~B}$ ) produced by SouthernClay ${ }^{\circledR}$ Inc. and Sepiolite ${ }^{\circledR}$ CD1 (coded as CD1) supplied by Tolsa ${ }^{\circledR}$ Inc.

Tab. 5. Polymer matrix characteristics.

\begin{tabular}{lllll}
\hline Commercial name & Sample code & $\begin{array}{l}\text { D-lactic acid } \\
\text { [wt.-\%] }\end{array}$ & $\begin{array}{l}\text { L-lactic acid } \\
\text { [wt.-\%] }\end{array}$ & $\mathrm{M}_{\mathrm{n}}$ \\
\hline PLA4042D $^{\circledR}$ & PLA1 & 8 & 92 & 130000 \\
PLA3000D $^{\circledR}$ & PLA2 & 2 & 98 & 94000 \\
\hline
\end{tabular}

Organic-inorganic blends for the further electrospinning were prepared by melt blending using an internal mixer (Brabender model W50E) at $60 \mathrm{rpm}$ and at $180{ }^{\circ} \mathrm{C}$ with a residence time of $5 \mathrm{~min}$. C30B was added to PLA at $10 \mathrm{wt} .-\%$, whereas CD1 was used at different amounts (5 and 10wt.-\%). Before melt blending, materials were dried in a vacuum oven $\left(14 \mathrm{~h}\right.$ at $50{ }^{\circ} \mathrm{C}$ and $4 \mathrm{~h}$ at $90{ }^{\circ} \mathrm{C}$ for polymer matrices and clays, respectively).

\section{Electrospinning of PLA and PLA-clay fibres}

PLA and PLA-clay blends were dissolved in 1,1,1,3,3,3-hexafluoro-2-propanol (Sigma-Aldrich, purity; 99\%). Polymer solution concentration was $7 \mathrm{wt} . \%$. Electrospinning was carried out using an apparatus consisting of a high-voltage generator (20kV from HVA B2 Electronic $\mathrm{GmbH}$ ), a metering pump, a syringe with a metallic nozzle (internal diameter $0.60 \mathrm{~mm}$ ) and a grounded collector $(55 \mathrm{~mm}$ diameter metal disk). Capillary-screen distance used was $15 \mathrm{~cm}$. The spinning was carried out at $35 \%$ relative humidity and $20{ }^{\circ} \mathrm{C}$.

\section{Characterization}

The surface morphology of the treated samples was studied using a Field-Emission Scanning Electron Microscope (FESEM, ZEISS SUPRA55VP). In addition, a Scanning Electron Microscope (SEM, LEO-1450VP apparatus), equipped with a Xray probe (INCA Energy Oxford, Cu-Ka X-ray source, $\mathrm{k}=1.540562 \AA$ ), was used to perform elemental analysis. The sample was fixed to conductive adhesive tapes and gold-metallised.

Fibre diameter size was statistically evaluated on 100 specimens for each sample using IMAGE J software from SEM images.

The thermal stability of the treated fabrics was evaluated by thermogravimetric (TG) analyses from 50 to $800^{\circ} \mathrm{C}$ with a heating rate of $10^{\circ} \mathrm{C} / \mathrm{min}$. A Pyris $1 \mathrm{TGA} Q 500$ 
analyzer was used, placing the samples in open alumina pans, in the presence of nitrogen or air atmosphere. The experimental error was estimated (after the instrumentation calibration) $\pm 1^{\circ} \mathrm{C}$ for the temperatures and $\pm 1 \%$ for the final residue.

Shear rate-dependent viscosity measurements were performed on electrospinning products at $0.005 \mathrm{ml} / \mathrm{min}$ out in an Anton Paar Physica MCR 301 rheometer, equipped with a PTD 200 Peltier temperature control device at $20^{\circ} \mathrm{C}$, using plateplate geometry $\left(75 \mathrm{~mm}\right.$ diameter, $1^{\circ}$ angle and $0.50 \mathrm{~mm}$ gap) in controlled shear rate mode. The shear rate was logarithmically increased from 0.01 to $10000 \mathrm{~s}-1$. Data were acquired and elaborated with the Rheoplus v2.66 (Anton Paar GmbH) software.

Conductivity of polymer solutions was measured on electrospinning products at $0.005 \mathrm{ml} / \mathrm{min}$ with an Eutech Instruments multi-parameter tester PC300 calibrated with a $1.413 \mathrm{mS} / \mathrm{cm}\left(\right.$ at $25^{\circ} \mathrm{C}$ ) standard solution.

Air permeability tests were performed following ISO 9237 standard with a Textest FX3300-20 on PLA2 and PLA2 added of 10 wt.-\% of C30B electrospun for 30 and $60 \mathrm{~min}(20 \mathrm{kV}$ of voltage, $15 \mathrm{~cm}$ of capillary-screen, at $0.010 \mathrm{ml} / \mathrm{min}$ of flow rate). The tests were directly carried out on the electrospun membranes that are more similar to fabrics with a texture rather than films. The electrospinning process employed in the present study does not allow to obtain aligned fibers.

This test permits to measure the gas transmission rate (GTR, $\mathrm{m}^{3} \mathrm{~s} / \mathrm{m}^{2}$ ) as the gas volume that flows through a surface unit of a porous material per unit of time. The error for each measurement of permeability was $\pm 0.002 \mathrm{~m}^{3} \mathrm{~s} / \mathrm{m}^{2} \mathrm{~Pa}$.

The air permeability $(\mathrm{P})$ was calculated using the following equation (1):

$P=\frac{G T R}{\Delta P}$

where $\Delta p$ represents the gas between inlet pressure (ambient pressure) and outlet pressure (downstream of the sample).

\section{Acknowledgements}

The authors would like to thank Prof. G. Malucelli and G. Camino for the fruitful discussions, Dr. A. Varesano, Dr. Montarsolo and Ing. G. Mazzuchetti for the support and DOCUP project 2000/2006, Ob. 2 of Regione Piemonte Reg. (CE) 1260/99 for the economical funding.

\section{References}

[1] Bhardwaj, N.; Kundu, S.C. Biotechnology Advances 2010, 28, 325.

[2] Teo, W.E.; Ramakrishna, S. Nanotechnol. 2006, 17, R89.

[3] Chronakis, I.S.; Mater J. J. Sci. Technol. 2005, 167, 283.

[4] Kim, G.M.; Michler, G.H.; Ania, F.; Balta Calleja, F.J. Polymer 2007, 48, 4814.

[5] Bianco, A.; lardino, G.; Bertarelli, C.; Miozzo, L.; Papagni, A.; Zerbi, G. Appl. Surf. Sci. 2007, 253, 8360.

[6] Chen, F.; Lee, C.N.; Teoh, S.H. Mater. Sci. Eng. C 2007, 27, 325.

[7] Chong, E.J.; Phan, T.T.; Lim, I.J.; Zhang, Y.Z.; Bay, B.H.; Ramakrishna, S.; Lim, C.T. Acta Biomater. 2007, 3, 321.

[8] Saeed, K.; Park, S.Y.; Lee, H.J.; Baek, J.B.; Huh, W.S. Polymer 2007, 47, 8019.

[9] You, Y.; Lee, S.W.; Lee, S.J.; Park, W.H. Mater. Lett. 2006, 60, 1331.

[10] Li, D.; Frey, M.W.; Baeumner, A.J. J. Membr. Sci. 2006, 279, 354. 
[11] Xu, X.; Yang, Q.; Wang, Y.; Yu, H.; Chen, X.; Jing, X. Eur. Polym. J. 2006, 42, 2081.

[12] You, Y.; Won Lee, S.; Youk, J.H.; Min, B.M.; Lee, S.J.; Park, W.H. Polym. Degrad. Stab. 2005, 90, 441.

[13] Han, S.O.; Youk, J.H.; Min, K.D.; Kang, Y.O.; Park, W.H. Mater. Letters 2008, 62, 759.

[14] Zhang, L.; Hsieh, Y.L. Carbohydr. Polym. 2008, 71, 196.

[15] Chen, C.; Wang, L., Huang, Y. Polymer 2007, 48, 5202.

[16] Kim, C.W.; Kim, D.S.; Kang, S.Y.; Marquez, M.; Joo, Y.L. Polymer 2006, 47, 5097.

[17] McCullen, S.D.; Stevens, D.R.; Roberts, W.A.; Ojha, S.S.; Clarke, L.I.; Gorga, R.E. Macromolecules 2007, 40, 997.

[18] Tripatanasuwan, S.; Zhong, Z.; Reneker, D.H. Polymer 2007, 48, 5742.

[19] Sui, X.; Shao, C.; Liu, Y. Polymer 2007, 48, 1459.

[20] Sawicka, K. M.; Gouma, P.J. J. Nanopart. Res. 2006, 8, 769.

[21] Utracki, L.A.; Sepehr, M.; Boccaleri, E. Polym. Adv. Technol. 2007, 18, 1.

[22] Sinha Ray, S.; Okamoto, M. Prog. Polym. Sci. 2003, 28, 1539.

[23] Zanetti, M.; Lomakin, L.S.; Camino, G. Macromol. Mater. Eng. 2000, $279,1$.

[24] Jose, M.V.; Steinert, B.W.; Thomas, V.; Dean, D.R.; Abdalla, M.A.; Price, G.; Janowski, G.M. Polymer 2007, 48, 1096.

[25] Xie, X.L.; Maia, Y.W.; Zhou, X.P. Mater. Sci. Eng. R 2005, 49, 89.

[26] Tian, M.; Gao, Y.; Liu, Y.; Liao, Y.; Xu, R.; Hedin, N.E.; Fong, H. Polymer 2007, $48,2720$.

[27] Li, L.; Bellan, L.M.; Craighead, H.G.; Frey, M.W. Polymer 2006, 47, 6208.

[28] Lee, Y.H.; Lee, J.H.; An, I.G.; Kim, C.; Lee, D.S.; Lee, Y.K.; Nam, J.D. Biomaterials 2005, 26, 3165.

[29] Pillin, I.; Montrelay, N.; Grohens, Y. Polymer 2006, 47, 4676.

[30] Martin, O.; Averous, L. Polymer 2001, 42, 6209.

[31] Reneker, D.H.; Chun, I. Nanotechnology 1996, 7, 216. 